\title{
The Effect of Nanoparticle Size on Cellular Binding Probability
}

\author{
Vital Peretz, ${ }^{1}$ Menachem Motiei, ${ }^{2}$ Chaim N. Sukenik, ${ }^{1}$ and Rachela Popovtzer ${ }^{2}$ \\ ${ }^{1}$ The Department of Chemistry, The Institute of Nanotechnology and Advanced Materials, Bar-Ilan University, \\ Ramat Gan 52900, Israel \\ ${ }^{2}$ Faculty of Engineering, The Institute of Nanotechnology and Advanced Materials, Bar-Ilan University, Ramat Gan 52900, Israel
}

Correspondence should be addressed to Rachela Popovtzer, rachela.popovtzer@biu.ac.il

Received 12 March 2012; Accepted 9 April 2012

Academic Editor: Zeev Zalevsky

Copyright () 2012 Vital Peretz et al. This is an open access article distributed under the Creative Commons Attribution License, which permits unrestricted use, distribution, and reproduction in any medium, provided the original work is properly cited.

\begin{abstract}
Nanoparticle-based contrast agents are expected to play a major role in the future of molecular imaging due to their many advantages over the conventional contrast agents. These advantages include prolonged blood circulation time, controlled biological clearance pathways, and specific molecular targeting capabilities. Recent studies have provided strong evidence that molecularly targeted nanoparticles can home selectively onto tumors and thereby increase the local accumulation of nanoparticles in tumor sites. However, there are almost no reports regarding the number of nanoparticles that bind per cell, which is a key factor that determines the diagnostic efficiency and sensitivity of the overall molecular imaging techniques. Hence, in this research we have quantitatively investigated the effect of the size of the nanoparticle on its binding probability and on the total amount of material that can selectively target tumors, at a single cell level. We found that $90 \mathrm{~nm}$ GNPs is the optimal size for cell targeting in terms of maximal Au mass and surface area per single cancer cell. This finding should accelerate the development of general design principles for the optimal nanoparticle to be used as a targeted imaging contrast agent.
\end{abstract}

\section{Introduction}

Imaging plays a critical role in overall cancer management; in diagnostics, staging, radiation planning, and evaluation of treatment efficiency. Conventional imaging technologies for cancer detection such as CT, MRI, and ultrasound can be categorized as structural imaging modalities. They are able to identify anatomical patterns and to provide basic information regarding tumor location, size, and spread based on endogenous contrast. However, these imaging modalities are not efficient in detecting tumors and metastases that

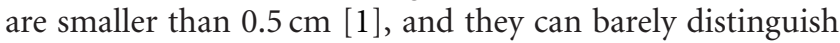
between benign and cancerous tumors. Molecular imaging is an emerging field that integrates molecular biology, chemistry, physics, and medicine in order to gain understanding regarding biological processes and to identify diseases based on molecular markers, which appear before the clinical presentation of the disease.

Recently, much research has focused on the development of targeted nanoparticles for use as contrast agents for molecular imaging. These include superparamagnetic nanoparticles for MRI [2-6], quantum dots for optical imaging [7-9], and gold nanoparticles (GNPs) for optical imaging $[10,11]$ and CT [12-14].

GNPs are a class of contrast agents with unique optical properties. They are well known for their strong interactions with visible light through the resonant excitations of the collective oscillations of the conduction electrons within the particles [15]. As a result, local electromagnetic fields near the particle can be many orders of magnitude higher than the incident fields, and the incident light around the resonantpeak wavelength is scattered very strongly. The resonance condition is determined from absorption and scattering spectroscopy and is found to depend on the shape, size, and dielectric constants of both the metal and the surrounding material. This localized surface plasmon resonance (LSPR) has led to the development of a wide range of biochemical detection assays [16] and various nanoprobes for optical imaging of cancer [17, 18].

In order to study whether incubation of the cancer cells with different sizes of GNPs can improve the coverage of the cells' surface, 15, 70, and $150 \mathrm{~nm}$ GNPs were incubated with head and neck cancer cells (A431) in different incubation orders, as illustrated in Table 2. We hypothesized that small 
GNPs, when introduced to the cells in a second cycle (after larger GNPs were incubated), will fill the gaps between the larger GNPs on the cells' surfaces.

GNPs are also an ideal CT contrast agents. The ability of CT to distinguish between different tissues is based on the fact that different tissues provide different degrees of X-ray attenuation, where the attenuation coefficient is determined by the atomic number and electron density of the tissue; the higher the atomic number and electron density, the higher the attenuation coefficient. The atomic number and electron density of gold $\left(79\right.$ and $19.32 \mathrm{~g} / \mathrm{cm}^{3}$, resp.) are much higher than those of the currently used iodine $\left(53\right.$ and $4.9 \mathrm{~g} / \mathrm{cm}^{3}$ ) and, therefore, gold induces a strong X-ray attenuation. When the gold particles are linked to specific-targeting ligands, such as monoclonal antibodies or peptides, these nanoparticles can selectively tag a wide range of medically important targets, for example, specific cancer cells, with high affinity and specificity. In addition, gold nanoparticles proved to be nontoxic and biocompatible in vivo $[19,20]$.

Recently, Hainfeld et al. [21] showed that GNPs can enhance the visibility of millimeter-sized human breast tumors in mice, and that active tumor targeting (with antiHer2 antibodies) is more efficient than passive targeting. They also showed that the specific uptake of the targeted GNPs in the tumor's periphery was 22-fold higher than in surrounding muscle. Another recent study demonstrated enhanced CT attenuation of bombesin-functionalized GNPs that selectively targeted cancer receptor sites that are overexpressed in prostate, breast, and small-cell lung carcinoma [22]. In our own research, [23], we recently demonstrated that a small tumor, which is currently undetectable through anatomical CT, is enhanced and becomes clearly visible by the molecularly-targeted GNPs. We further showed that the CT number of molecularly targeted head and neck tumor is over five times higher than the corresponding CT number of an identical but untargeted tumor, and that active tumor targeting is more efficient and specific than passive targeting.

These studies have provided strong evidence that nanoparticles accumulate in vivo on the tumor. However, there are almost no reports regarding the number of nanoparticles that bind per cell, which is a key factor that determines the diagnostic efficiency and sensitivity of the overall molecular imaging techniques. Hence, in this research, we have quantitatively investigated the effect of the size of the nanoparticle on its binding probability and on the total amount of material that can selectively target tumors, on a single cell level. We have further investigated the ability to increase the amount of contrast material that binds per cell by simultaneously targeting nanoparticles in different sizes or in consequent cycles.

\section{Methods}

2.1. Gold Nanospheres Synthesis, Conjugation, and Characterization. Gold nanospheres $(10,15$, and $30 \mathrm{~nm})$ were synthesized by citrate reduction according to the method described by Turkevitch et al. [24]. Larger GNPs (70, 90, and $150 \mathrm{~nm}$ ) were synthesized using the seed mediated growth method [25]. Briefly, gold seeds were synthesized using an aqueous $\mathrm{HAuCl}_{4}$ solution $(0.25 \mathrm{~mL}$ of $0.05 \mathrm{M}$ solution $)$ and adding it to $50 \mathrm{~mL} \mathrm{H}_{2} \mathrm{O}$ and boiling. After boiling, $1.75 \mathrm{~mL}$ of $1 \%$ citrate $(1.75 \mathrm{~mL}$ of a solution that was $114 \mathrm{mg}$ in $10 \mathrm{~mL} \mathrm{H}_{2} \mathrm{O}$ ) were added to the solution and stirring was continued for $20 \mathrm{~min}$. The solution was cooled to room temperature and used directly for further experiments. This method produced gold nanospheres with a diameter of $15 \mathrm{~nm}$ [26]. In order to enlarge the nanoparticles, $170 \mathrm{~mL}$ DD water along with $0.44 \mathrm{~mL}$ of $1.4 \mathrm{M} \mathrm{HAuCl}_{4}$ and $26 \mathrm{~mL}$ seed solution to make $90 \mathrm{~nm}$ GNPs or $31 \mathrm{~mL}$ seed solution to make $70 \mathrm{~nm}$ GNPs was added to a $400 \mathrm{~mL}$ Erlenmeyer flask. Then, $3.72 \mathrm{~mL}$ of $0.1 \mathrm{M}$ 2-mercaptosuccinic acid (MSA) was added as the reducing agent. The solution was stirred for $1 \mathrm{~min}$ and left overnight. According to this method 70 and $90 \mathrm{~nm}$ gold nanospheres were synthesized.

In order to prevent aggregation and to stabilize the particles in physiological solutions, a layer of polyethylene glycol (mPEG-H) was absorbed onto the GNPs. This layer also provides the chemical groups that are required for antibody conjugation (SH-PEG-COOH). The SH-PEG layer consisted of a mixture of 15\% SH-PEG-COOH (Mw. 3400) and 85\% SH-PEG-methyl (Mw. 5000), both obtained from Creative PEGWorks, Winston Salem, NC. The PEG solution was added to the GNPs solution and stirred for 3 hours. It was then centrifuged in order to get rid of excess PEG citrate and MSA. The ratio of PEG molecules to GNPs was calculated based on a footprint area of $0.35 \mathrm{~nm}^{2}$ [27].

2.1.1. Conjugation of Antibodies to GNPs. In order to specifically bind to the SCC cancer cells, anti-EGFR (epidermal growth factor receptor, Erbitux, Merck KGaA), antibodies, which bind exclusively to the EGF receptor, were conjugated to the outer coating of the nanoparticles. The interaction between the GNP and the antibody are based on electrostatic attraction between the negatively charged heterofunction PEG (SH-PEG-COOH) and the positive segment of the antibody in $\mathrm{pH}$ 7.4.

EGFR conjugation to $70 \mathrm{~nm}$ GNPs: $1.31 \mathrm{mg}$ of SH-PEG$\mathrm{COOH}$ and $11 \mathrm{mg}$ of SH-PEG were dissolved in $2 \mathrm{~mL} \mathrm{DD}$ water and added to the GNPs solution with stirring for 3 hours. The solution was centrifuged and $15 \mathrm{~mL}$ of $5 \mathrm{mg} / \mathrm{mL}$ of anti-EGFR were added to the solution with stirring for 1 hour in order to get rid of excess anti-EGFR. The solution was kept at $4^{\circ} \mathrm{C}$. The conjugation of anti-EGFR to all other GNPs sizes was achieved using the same method with different quantities.

2.2. In Vitro Cell Targeting Study Using GNPs. In order to study the effect of nanoparticle size on its binding probability, 15, 70, and $150 \mathrm{~nm}$ GNPs were incubated with head and neck cancer cells (A431); (Group A with $15 \mathrm{~nm}$ GNPs, group B with $70 \mathrm{~nm}$ GNPs, and group C with $150 \mathrm{~nm}$ GNPs.) A431 cells $\left(1.5 \times 10^{6}\right)$ in $5 \mathrm{~mL}$ DMEM medium containing $5 \%$ FCS, $0.5 \%$ penicillin, and $0.5 \%$ glutamine were incubated for a quantitative cell binding study (each experimental group was run in triplicate). Each group was incubated 3 times with access amount of anti-EGFR-coated GNPs for 30 minutes at $37^{\circ} \mathrm{C}$. After incubation, the medium 
TABLE 1: The effect of each additional incubation cycle on the amount of contrast material that binds per cell. Each cell sample contained $1.5 \times 10^{6}$ cells. The cells were incubated with the different sized GNPs in consequent cycles for $30 \mathrm{~min}$ at $37^{\circ} \mathrm{C}$ each cycle. Each experimental group was run in triplicate. The GNPs were added in excess.

\begin{tabular}{lccc}
\hline The effect of each additional incubation cycle & Cell type & GNPs size $(\mathrm{nm})$ & Comment \\
\hline A & A431 & 90 & \\
B & A431 & 90,90 & The cells were incubated with the GNPs in consequent cycles \\
C & A431 & 90,30 & \\
D & A431 & $90,30,10$ & \\
\hline
\end{tabular}

TABLE 2: The effect of incubation of different sized GNPs in consequent cycles experiment. Each cell sample contained $1.5 \times 10^{6}$ cells. The cells were incubated with the different sized GNPs in consequent cycles for $30 \mathrm{~min}$ at $37^{\circ} \mathrm{C}$ each cycle. Each experimental group was run in triplicate. The GNPs were added in excess amount.

\begin{tabular}{lccl}
\hline $\begin{array}{l}\text { The effect of combination of different sized } \\
\text { GNPs in consequent cycles }\end{array}$ & Cell type & GNPs size (nm) & Comment \\
\hline A & A431 & $15,70,150$ & The cells were incubated with the \\
B & A431 & $150,70,15$ & different size of GNPs in \\
C & A431 & $150,150,150$ & consequent cycles \\
\hline
\end{tabular}

was washed twice with PBS followed by addition of $1 \mathrm{~mL}$ of aqua-regia. After evaporation of the acid, the sediment was dissolved in $5 \mathrm{~mL}$ of $0.05 \mathrm{M} \mathrm{HCl}$. The gold concentrations of the samples were quantified by Flame Atomic Absorption Spectroscopy (SpectrAA 140, Agilent Technologies).

We have further investigated whether we are able to increase the amount of contrast material that binds per cell by subsequent cycles of binding, and how many GNPs can bind to a single cancer cell after each cycle of incubation. Therefore, 90, 30, and $10 \mathrm{~nm}$ GNPs were incubated in consequent cycles with the A431 cells (each cycle for $30 \mathrm{~min}$ at $37^{\circ} \mathrm{C}$ ) as illustrated in Table 1 . After each incubation cycle, the amount of gold (Au mass/cell) was measured using FAAS. Then, the number of GNPs that were bound in each cycle could be calculated.

\section{Results and Discussion}

3.1. Gold Nanospheres Synthesis, Conjugation and Characterization. We have successfully synthesized GNPs in various sizes, ranging from $10 \mathrm{~nm}$ up to $150 \mathrm{~nm}$. Figure 1 shows TEM images of 10, 30, 70, and $150 \mathrm{~nm}$ GNPs. As can be seen, the small GNPs $(\sim 10 \mathrm{~nm})$ have a relatively large size distribution (25\%, Figure 1(a)), while particles that are larger than $30 \mathrm{~nm}$ are more homogeneous with a very narrow size distribution (Figures 1(b), 1(c), and 1(d)). The surface plasmon resonances of the various size GNPs are illustrated in Figure 2. It can be seen that when the nanospheres are enlarged there is a red shift in the surface plasmon resonance of the particles (from $525 \mathrm{~nm}$ to $580 \mathrm{~nm}$ ).

GNPs were successfully coated with PEG and anti-EGFR antibody. The antibody conjugated GNPs were stable for up to three months, confirmed by their maintenance of the same plasmon resonance.

3.2. Quantitative Investigation of the Size Effect of the Nanoparticle on Its Binding Probability. Before studying the effect of nanoparticle size on its binding probability, we have evaluated the specificity of the interaction between the antibody-coated GNPs and the A431 SCC cancer cells (which highly express the EGF receptor). Two types of GNPs ( $50 \mu \mathrm{L}$ of $25 \mathrm{mg} / \mathrm{mL}$ ) were introduced to the SCC head and neck cancer cells $\left(2.5 \times 10^{6}\right.$ cells $)$. The first was specifically coated with anti-EGFR antibody, while the second, which was used as a negative control, was coated with a nonspecific antibody (anti-Rabbit IgG). Atomic absorption spectroscopy measurements quantitatively demonstrated that the active tumor targeting (anti-EGFR coated GNPs) was significantly more specific than the control experiment (anti-Rabbit IgG coated GNPs). The A431 cells took up $26.3 \pm 2.3 \mu \mathrm{g}$ of targeted GNPs $\left(3.9 \times 10^{4}\right.$ GNPs per A431 cell); while parallel cells in the negative control experiment absorbed only $0.2 \pm 0.01 \mu \mathrm{g}$ of GNPs $\left(3.4 \times 10^{3}\right.$ GNPs per cell $)$. Our results correlate well with previously published studies, which report that head and neck SCC express from $2 \times 10^{4}$ to $2 \times 10^{6}$ EGFRs/cell $[28,29]$.

In order to quantitatively investigate the effect of nanoparticle size on its binding probability (on a single cell level), head and neck cancer cells were incubated with different size GNPs $(15,70$, and $150 \mathrm{~nm})$ for $30 \mathrm{~min}$. For maximal binding, the particles were incubated three times with the cancer cells. Figure 3 shows the total amount of gold (Au mass/cell) that binds per cell for nanoparticles of different sizes $(15,70$, and $150 \mathrm{~nm})$. The results clearly demonstrate that larger particles produce larger amounts of gold per cancer cell. For the $15 \mathrm{~nm}$ GNPs, only $0.0018 \mathrm{ng}$ of gold was bound to a single cancer cell (A431) while for the largest particles, $150 \mathrm{~nm}, 0.145 \mathrm{ng}$ of gold was bound to a single cancer cell.

Once we have quantitatively measured (using FAAS) the total amount of gold that was bound to a single cancer cell, the exact number of nanoparticles and the GNPs' surface area per cancer cell could then be calculated. Table 3 shows the total Au mass, the number of GNPs of different sizes, 


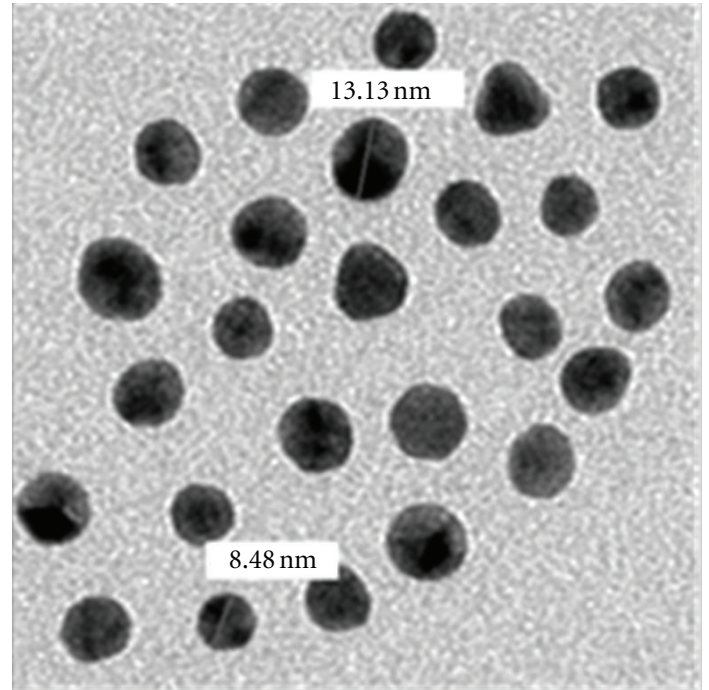

(a)

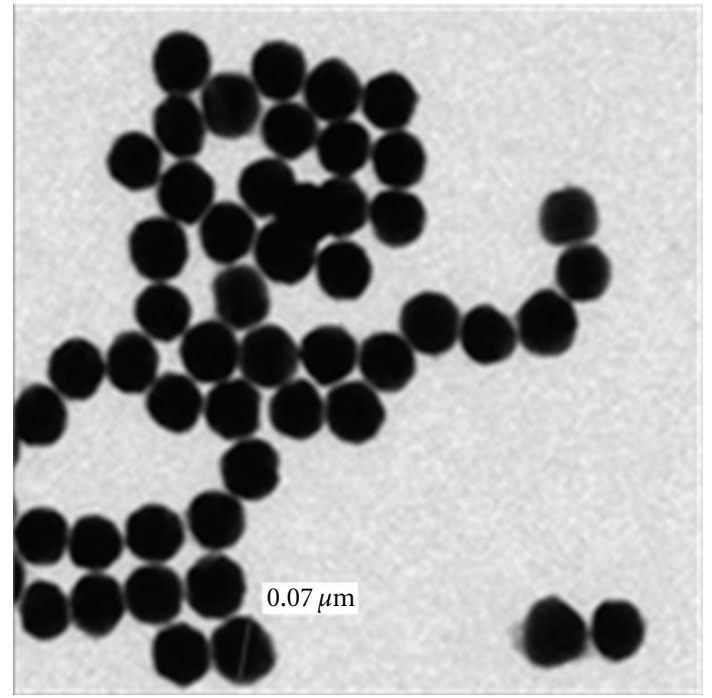

(c)

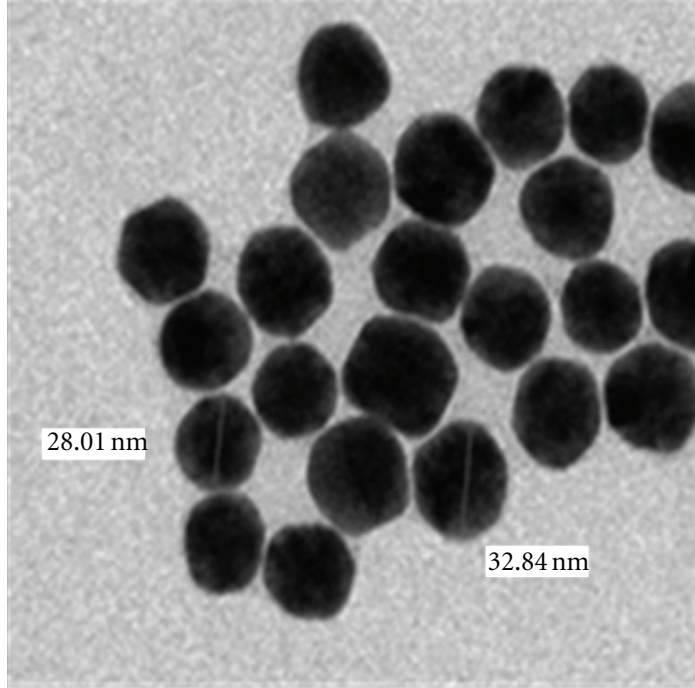

(b)

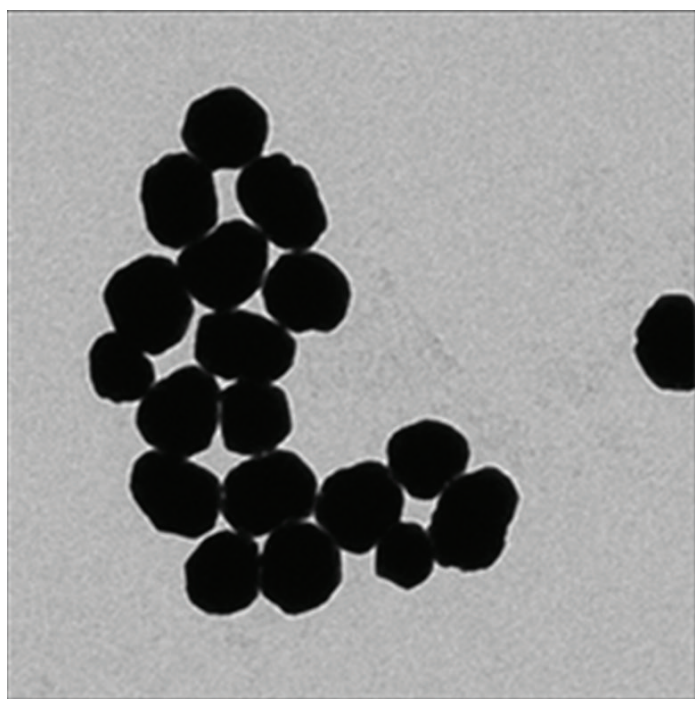

(d)

Figure 1: TEM images of different sized GNPs (a) $10 \mathrm{~nm}$, (b) $30 \mathrm{~nm}$, (c) $70 \mathrm{~nm}$, and (d) $150 \mathrm{~nm}$.

TABle 3: Quantitative analysis: number of GNPs of different sizes that are bound to a single cancer cell, total Au mass and the GNPs' surface area per single cell.

\begin{tabular}{lccc}
\hline $\begin{array}{l}\text { GNP size } \\
(\mathrm{nm})\end{array}$ & $\begin{array}{c}\text { Number of } \\
\text { GNP per cell }\end{array}$ & $\begin{array}{c}\text { Au/cell } \\
(\mathrm{ng})\end{array}$ & $\begin{array}{c}\text { Total surface area } \\
\left(\mathrm{m}^{2}\right)\end{array}$ \\
\hline 15 & 54000 & 0.00186 & $3.8 \times 10^{-11}$ \\
30 & 39000 & 0.01 & $1.1 \times 10^{-10}$ \\
90 & 12000 & 0.124 & $3.05 \times 10^{-10}$ \\
150 & 4200 & 0.145 & $2.9 \times 10^{-10}$ \\
\hline
\end{tabular}

and the surface area of the GNPs that are bound to a single cancer cell.

These results clearly demonstrate that smaller particles have a higher probability to bind to cancer cells (via antibodyantigen interaction) than larger particles (Figure 4(a)). The probability of $15 \mathrm{~nm}$ GNPs to bind to cancer cells is about 13 times more than the probability of $150 \mathrm{~nm}$ GNPs. However, larger particles produce larger amounts of $\mathrm{Au}$ mass per cell, as well as larger surface area, as illustrated in Figures 4(b) and 4(c). Nevertheless, particles larger than $90 \mathrm{~nm}$ only slightly increased the Au mass/cell and the surface area/cell.

We have further investigated whether incubation of the cancer cells with different sizes of GNPs can improve the coverage of the cells' surface. We have hypothesized that small GNPs, when introduced to the cells in a second cycle (after larger GNPs were incubated), will fill the gaps between the larger GNPs on the cells' surface. However, as can be seen in Figure 5, maximum coverage (or max. Au mass/cell) was obtained for the largest GNPs (column C, 0.14 ngr Au/cell). It has also been demonstrated that the order of the incubation (between the cells and the GNPs) is critical. When $15 \mathrm{~nm}$ GNPs were introduced first to the cells, overall, a much smaller amount of gold was bound (column A). 


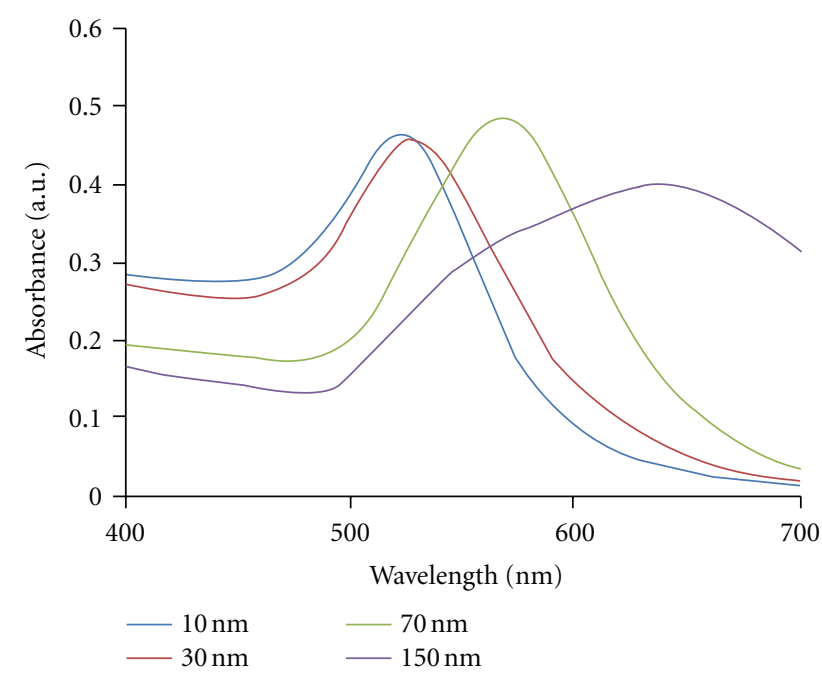

Figure 2: UV-Vis spectroscopy of 10, 30, 70, and $150 \mathrm{~nm}$ gold nanospheres.

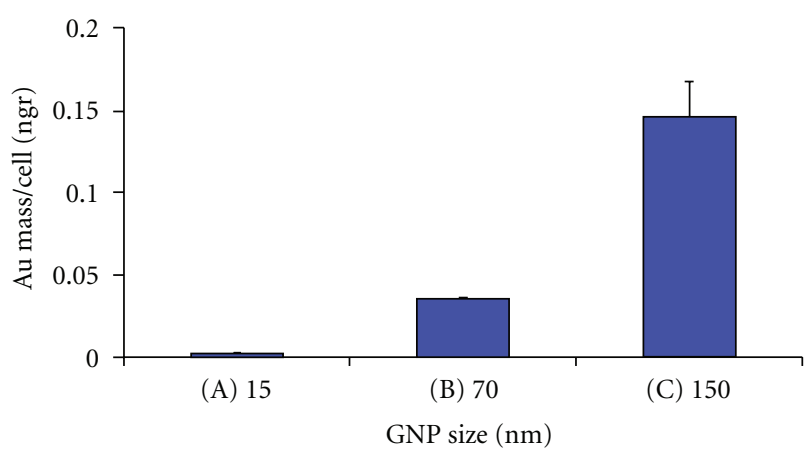

FIGURE 3: Quantitative measurements using FAAS of Au mass/cell for different sizes of GNPs. Each cell sample contained $1.5 \times$ $10^{6}$ cells and was incubated 3 times with the GNPs. The GNPs were added in excess. The error bars represent the standard deviation of three samples.

We have further investigated whether we are able to increase the amount of contrast material that binds per cell by consequent cycles of binding, and how many GNPs were bound to a single cancer cell after each cycle of incubation. As seen in Figure 6, the first incubation is the most critical. After one incubation with $90 \mathrm{~nm}$ GNPs, $0.1048 \mathrm{ngr}$ of gold (=14258 GNPs) was bound to a single cancer cell. In the second cycle of incubation with $90 \mathrm{~nm}$ GNPs (Figure 6, column B), only a relatively small number of GNPs were bound (2742 $90 \mathrm{~nm}$ GNPs (20\%)). Adding smaller GNPs (30 and $15 \mathrm{~nm}$, Figure 6 columns $C$ and D) barely influenced the amount of gold per cell ( $0.0015 \mathrm{ngr}$ ( $577230 \mathrm{~nm}$ GNPs (1\%) for $30 \mathrm{~nm}$ GNPs, and $0 \mathrm{ngr}$ for the $15 \mathrm{~nm}$ GNPs). It has been also demonstrated that the first antibody antigen interaction (first incubation between the cells and the GNPs) is the most effective (Figure 6, column A).

\section{Summery and Conclusions}

In order to develop general design principles for nanoparticles to be used as in vivo imaging contrast agents, we

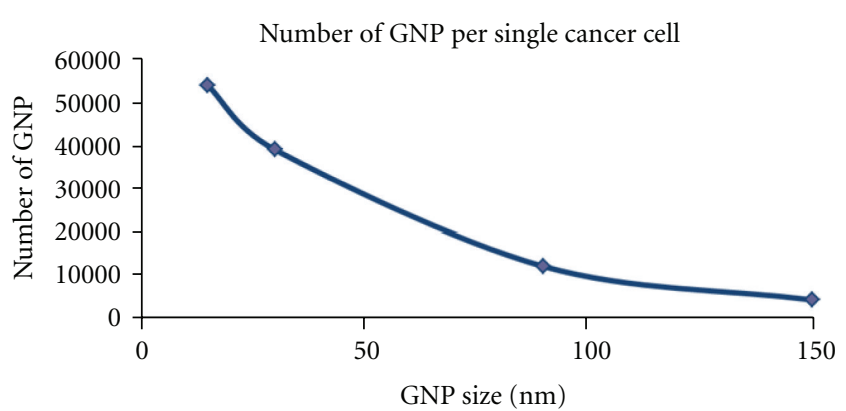

(a)

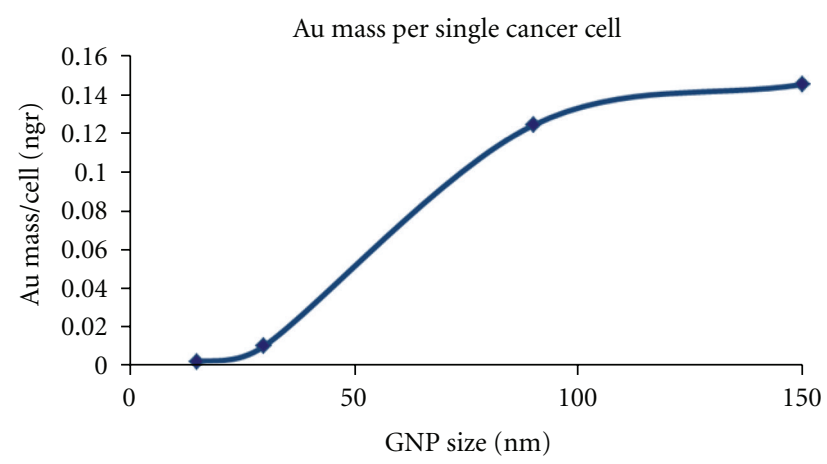

(b)

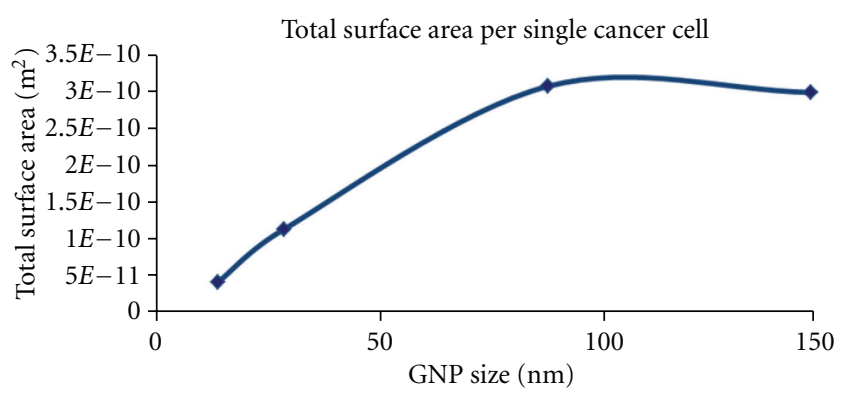

(c)

FIGURE 4: correlation between GNPs' sizes, number, mass and surface area for a single cancer cell: (a) number of GNP per cell, (b) Au mass/cell, (c) surface area/cell.

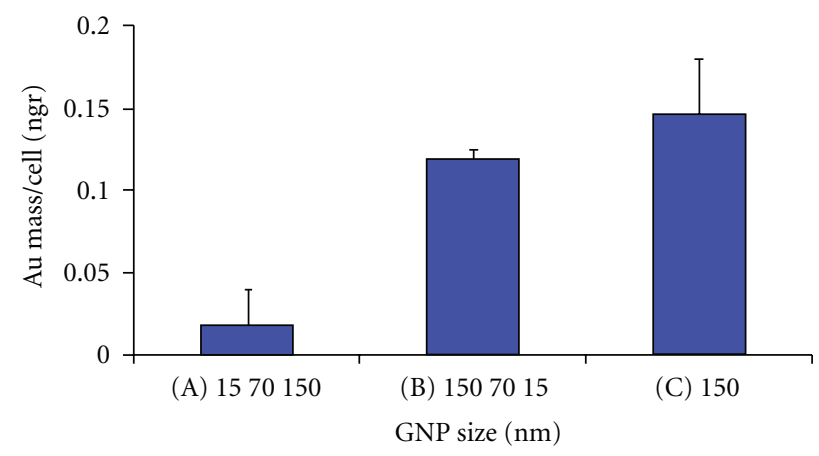

Figure 5: Atomic absorption measurement of gold per cell. Each column shows 3 incubations differing in GNP size and order of application. 


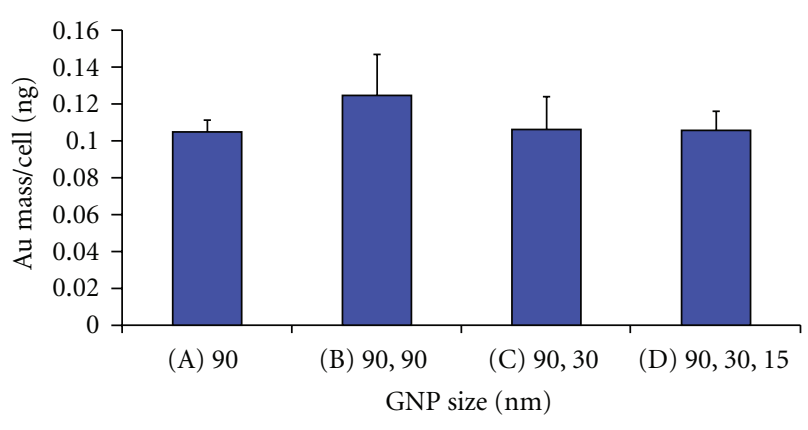

Figure 6: Atomic absorption measurement of gold concentration per cell for various cycles and different sizes of GNPs.

have quantitatively investigated the effect of the size of the nanoparticle on its binding probability and on the total amount of material that can selectively target tumors, on a single cell level. We found that $90 \mathrm{~nm}$ GNPs are the optimal size for cell targeting both in terms of maximal Au mass and surface area per single cell. For in vivo applications, $90 \mathrm{~nm}$ is in the right size range since the particles should be larger than $\sim 15 \mathrm{~nm}$ to avoid rapid clearance by the kidneys or uptake in the liver, and smaller than $\sim 150 \mathrm{~nm}$ to avoid filtration in the spleen [30]. It has been demonstrated that smaller particles, despite having higher binding probability, produce a smaller amount of Au mass per cell as well as a smaller surface area. Particles that are larger than $90 \mathrm{~nm}$ only slightly increased the Au mass/cell and decreased the surface area/cell. It has been also demonstrated that the first incubation is the most critical. However, subsequent incubation can increase the amount of contrast material by about $20 \%$. The results of this study should accelerate the development of general design principles for the optimal nanoparticle to be used as a targeted imaging contrast agent.

\section{References}

[1] H. Rusinek, D. P. Naidich, G. McGuinness et al., "Pulmonary nodule detection: low-dose versus conventional CT," Radiology, vol. 209, no. 1, pp. 243-249, 1998.

[2] R. Lamerichs, "MRI-based molecular imaging using nanoparticles," Cellular Oncology, vol. 30, no. 2, p. 100, 2008.

[3] C. Sun, O. Veiseh, J. Gunn et al., "In vivo MRI detection of gliomas by chlorotoxin-conjugated superparamagnetic nanoprobes," Small, vol. 4, no. 3, pp. 372-379, 2008.

[4] R. Kopelman, Y. E. Lee Koo, M. Philbert et al., "Multifunctional nanoparticle platforms for in vivo MRI enhancement and photodynamic therapy of a rat brain cancer," Journal of Magnetism and Magnetic Materials, vol. 293, no. 1, pp. 404410, 2005.

[5] Y. E. L. Koo, G. R. Reddy, M. Bhojani et al., "Brain cancer diagnosis and therapy with nanoplatforms," Advanced Drug Delivery Reviews, vol. 58, no. 14, pp. 1556-1577, 2006.

[6] A. M. Neubauer, H. Sim, P. M. Winter et al., "Nanoparticle pharmacokinetic profiling in vivo using magnetic resonance imaging," Magnetic Resonance in Medicine, vol. 60, no. 6, pp. 1353-1361, 2008.

[7] X. H. Gao and S. M. Nie, "Long-circulating QD probes for invivo tumor imaging," Nanosensing: Materials and Devices, vol. 5593, pp. 292-299, 2004.
[8] P. Diagaradjane, J. M. Orenstein-Cardona, N. E. ColónCasasnovas et al., "Imaging epidermal growth factor receptor expression in vivo: pharmacokinetic and biodistribution characterization of a bioconjugated quantum dot nanoprobe," Clinical Cancer Research, vol. 14, no. 3, pp. 731-741, 2008.

[9] Y. Guo, D. Shi, J. Lian et al., "Quantum dot conjugated hydroxylapatite nanoparticles for in vivo imaging," Nanotechnology, vol. 19, no. 17, Article ID 175102, 2008.

[10] C. Loo, A. Lowery, N. Halas, J. West, and R. Drezek, "Immunotargeted nanoshells for integrated cancer imaging and therapy," Nano Letters, vol. 5, no. 4, pp. 709-711, 2005.

[11] A. M. Gobin, M. H. Lee, N. J. Halas, W. D. James, R. A. Drezek, and J. L. West, "Near-infrared resonant nanoshells for combined optical imaging and photothermal cancer therapy," Nano Letters, vol. 7, no. 7, pp. 1929-1934, 2007.

[12] R. Popovtzer, A. Agrawal, N. A. Kotov et al., "Targeted gold nanoparticles enable molecular CT imaging of cancer," Nano Letters, vol. 8, no. 12, pp. 4593-4596, 2008.

[13] D. Kim, S. Park, H. L. Jae, Y. J. Yong, and S. Jon, “Antibiofouling polymer-coated gold nanoparticles as a contrast agent for in vivo X-ray computed tomography imaging," Journal of the American Chemical Society, vol. 129, no. 24, pp. 7661-7665, 2007.

[14] J. F. Hainfeld, D. N. Slatkin, T. M. Focella, and H. M. Smilowitz, "Gold nanoparticles: a new X-ray contrast agent," British Journal of Radiology, vol. 79, no. 939, pp. 248-253, 2006.

[15] K. H. Su, Q. H. Wei, X. Zhang, J. J. Mock, D. R. Smith, and S. Schultz, "Interparticle coupling effects on plasmon resonances of nanogold particles," Nano Letters, vol. 3, no. 8, pp. 10871090, 2003.

[16] C. T. Campbell and G. Kim, "SPR microscopy and its applications to high-throughput analyses of biomolecular binding events and their kinetics," Biomaterials, vol. 28, no. 15, pp. 2380-2392, 2007.

[17] P. K. Jain, I. H. ElSayed, and M. A. El-Sayed, "Au nanoparticles target cancer," Nano Today, vol. 2, no. 1, pp. 18-29, 2007.

[18] I. H. El-Sayed, X. Huang, and M. A. El-Sayed, "Surface plasmon resonance scattering and absorption of anti-EGFR antibody conjugated gold nanoparticles in cancer diagnostics: applications in oral cancer," Nano Letters, vol. 5, no. 5, pp. 829834, 2005.

[19] E. E. Connor, J. Mwamuka, A. Gole, C. J. Murphy, and M. D. Wyatt, "Gold nanoparticles are taken up by human cells but do not cause acute cytotoxicity," Small, vol. 1, no. 3, pp. 325-327, 2005.

[20] T. S. Hauck, A. A. Ghazani, and W. C. W. Chan, "Assessing the effect of surface chemistry on gold nanorod uptake, toxicity, and gene expression in mammalian cells," Small, vol. 4, no. 1, pp. 153-159, 2008.

[21] J. F. Hainfeld, M. J. O'Connor, F. A. Dilmanian, D. N. Slatkin, D. J. Adams, and H. M. Smilowitz, "Micro-CT enables microlocalisation and quantification of Her2-targeted gold nanoparticles within tumour regions," British Journal of Radiology, vol. 84, no. 1002, pp. 526-533, 2011.

[22] N. Chanda, V. Kattumuri, R. Shukla et al., "Bombesin functionalized gold nanoparticles show in vitro and in vivo cancer receptor specificity," Proceedings of the National Academy of Sciences of the United States of America, vol. 107, no. 19, pp. 8760-8765, 2010.

[23] T. Reuveni, M. Motiei, Z. Romman, A. Popovtzer, and R. Popovtzer, "Targeted gold nanoparticles enable molecular CT imaging of cancer: an in vivo study," International Journal of Nanomedicine, vol. 6, pp. 2859-2864, 2011. 
[24] J. Turkevich, P. C. Stevenson, and J. Hillier, "A study of the nucleation and growth processes in the synthesis of colloidal gold," Discussions of the Faraday Society, vol. 11, pp. 55-75, 1951.

[25] J. Niu, T. Zhu, and Z. Liu, “One-step seed-mediated growth of 30-150 nm quasispherical gold nanoparticles with 2mercaptosuccinic acid as a new reducing agent," Nanotechnology, vol. 18, no. 32, Article ID 325607, 2007.

[26] G. Frens, "Controlled nucleation for regulation of particle-size in monodisperse gold suspensions," Nature-Physical Science, vol. 241, no. 105, pp. 20-22, 1973.

[27] W. P. Wuelfing, S. M. Gross, D. T. Miles, and R. W. Murray, "Nanometer gold clusters protected by surface-bound monolayers of thiolated poly(ethylene glycol) polymer electrolyte," Journal of the American Chemical Society, vol. 120, no. 48, pp. 12696-12697, 1998.

[28] R. Todd and D. T. W. Wong, "Epidermal growth factor receptor (EGFR) biology and human oral cancer," Histology and Histopathology, vol. 14, no. 2, pp. 491-500, 1999.

[29] P. Stanton, S. Richards, J. Reeves et al., "Epidermal growth factor receptor expression by human squamous cell carcinomas of the head and neck, cell lines and xenografts," British Journal of Cancer, vol. 70, no. 3, pp. 427-433, 1994.

[30] F. Hallouard, N. Anton, P. Choquet, A. Constantinesco, and T. Vandamme, "Iodinated blood pool contrast media for preclinical X-ray imaging applications-a review," Biomaterials, vol. 31, no. 24, pp. 6249-6268, 2010. 

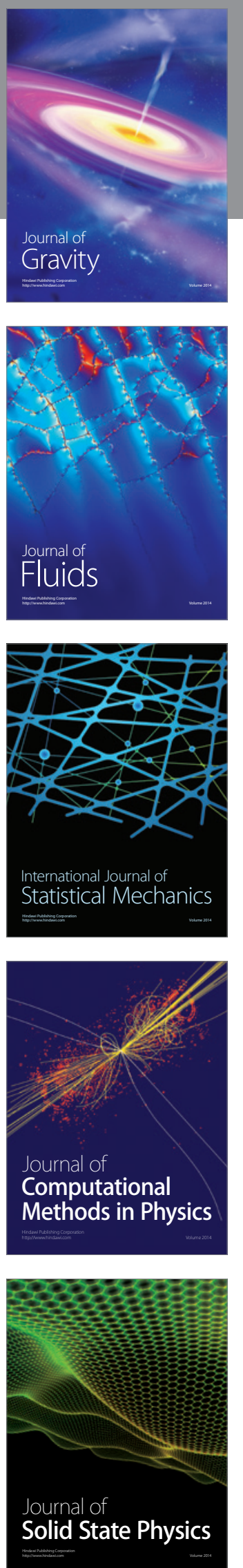

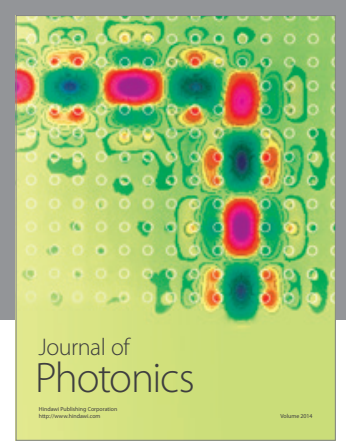

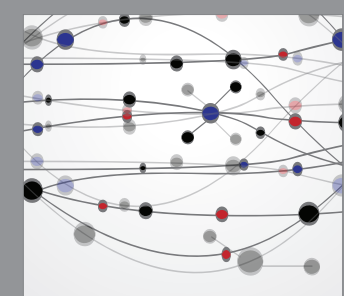

The Scientific World Journal
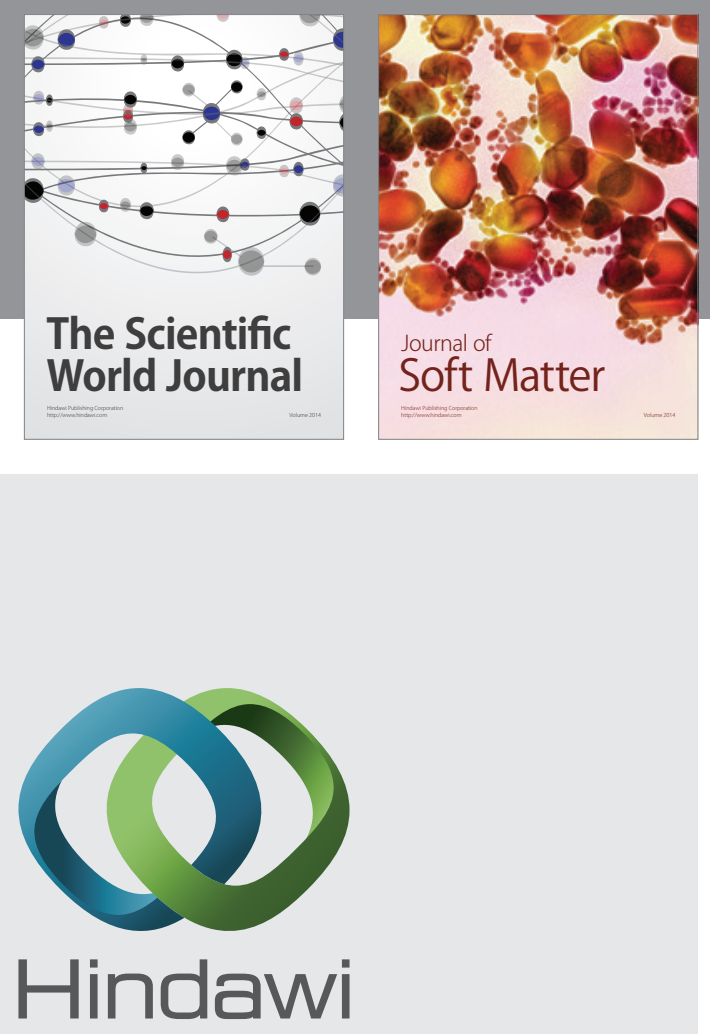

Submit your manuscripts at

http://www.hindawi.com
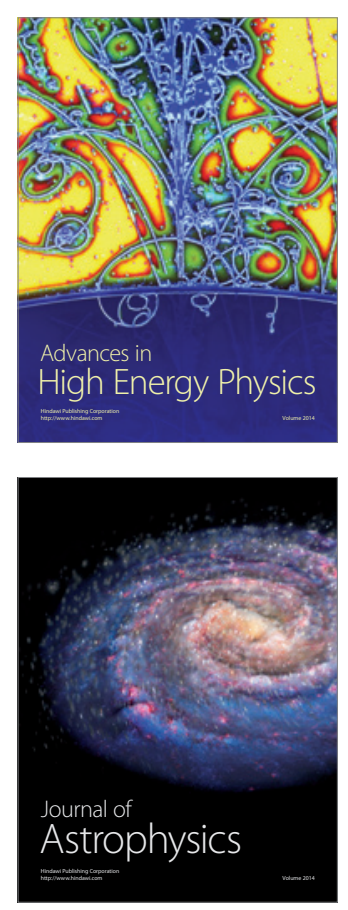
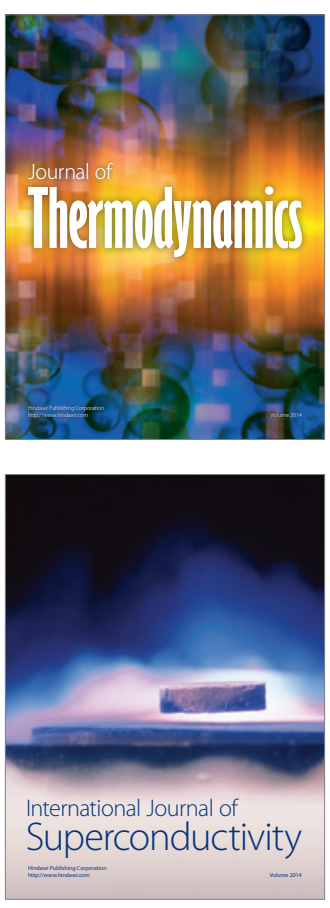
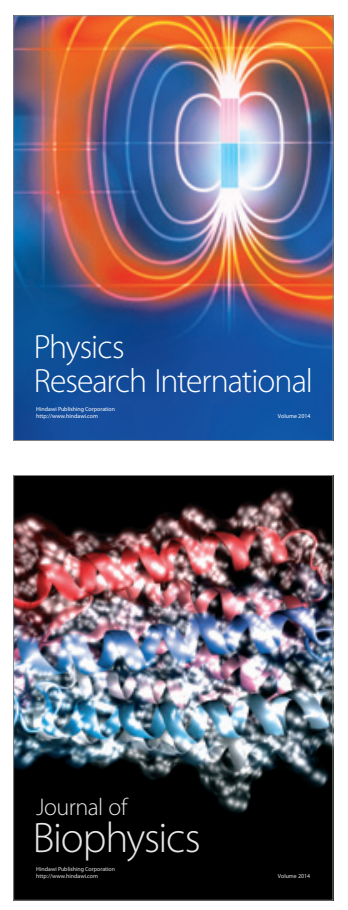
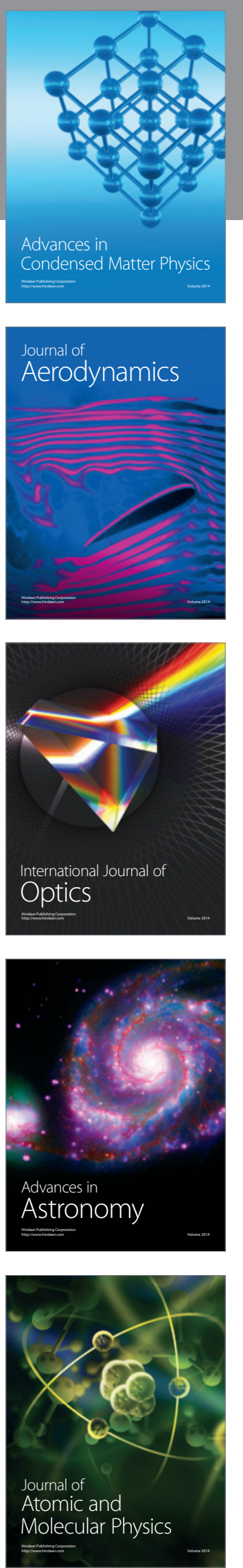